\title{
Research on Testing Technology of Building Engineering Materials
}

\author{
Renwei Shan ${ }^{1}$ \\ ${ }^{1}$ Jiangxi Open University,Nanchang, China,330001
}

\begin{abstract}
With the rapid development of China's economy, the construction of urbanization is also accelerating, and social development puts forward higher standards for construction projects. In building engineering, one of the important factors affecting the quality of building engineering is building engineering materials. At present, there are many kinds of building materials involved in engineering operations. Only by conscientiously grasping the quality of all kinds of building materials and the building materials strictly in accordance with the technical specifications can the building quality be assured. Good testing technology of building engineering materials not only defends the building quality of our country but also protects people's life and property safety.
\end{abstract}

\section{Introduction}

Since the reform and opening up, especially after entering the 21 century, the society of our country has undergone great changes, and the cause of socialist construction has achieved fruitful results. China's economy and society have been greatly developed. At present, our country is speeding up the work of urbanization. $x$ There are many projects under construction in every city of our country, tall buildings are connected to each other, commercial buildings and residential areas are springing up. The rapidly developing construction industry has made an important contribution to promoting national economic development and has become one of the pillar industries in China. At present, the development of the construction engineering industry is also facing a lot of problems, including the quality of construction engineering. As we all know, the quality of construction engineering mainly depends on construction engineering materials. In order to improve the construction quality of our country and realize the high-quality development of the construction industry, it is necessary to carry out in-depth research on construction engineering materials. The most used, the highest quality requirements, the most obvious impact of materials are steel, cement, concrete. Strictly control the quality of related materials, to improve the quality of engineering construction has a decisive role.

\section{Significance of Inspection of Building Engineering Materials}

The so-called building engineering materials refer to the general name of materials with various special functions used in the process of carrying out engineering construction or civil engineering construction. Different materials affect the structure and outline of the building inside and outside. Building materials can be divided into structural materials, decorative materials, and special materials. This paper will discuss the significance of building engineering material testing technology to the social development and economic construction of our country. Construction engineering material testing technology plays a very important role in the process of industrial development and innovation.

First of all, the construction engineering inspection technology can effectively solve the construction quality problems in the development of the construction industry. In recent years, the rapid development of urbanization in China has solved the housing problem that the Chinese have not been completely solved for thousands of years, and the traffic conditions have also been greatly improved. However, this process also reveals that the quality of construction is not high, the quality stability is not good, and some construction projects have serious quality risks. There are many reasons, the most important of which is the quality of building materials. Only high quality building materials can complete high quality building works. Poor construction materials will greatly reduce the quality of the building, which will easily lead to a decline in the life of the building, and even endanger the personal safety of the staff in the process of building implementation. Therefore, before the construction of the project, the quality inspection of the incoming building materials can prevent the gradual development and ensure the quality of the construction project.

Secondly, the benefit of building engineering can be effectively improved by carrying out the inspection of building engineering materials. The inspection of building materials can greatly improve the safety performance of building engineering materials. Whether the performance 
index marked by the manufacturer meets the standard can be verified by testing. When the materials of many manufacturers can reach the quality standard, we can choose the enterprise with the highest cost-performance ratio, and finally realize the purpose of improving the efficiency of construction engineering.

In addition, the use of building engineering materials detection technology can effectively update the technology of building materials in our country. At present, due to the imbalance of regional economic development, there are many kinds of materials, technologies, and processes in the field of building engineering materials. New technologies, processes, and materials are constantly developing in some developed regions. Through the construction engineering material inspection technology can popularize these good materials and the technology. Optimal material procurement and technical solutions to accelerate healthy industry development.

\section{Characteristics of Building Engineering Materials and Analysis of Specific Testing Techniques}

\subsection{Characteristics of Building Engineering Materials}

There are many different types of materials in building engineering, including steel bars, cement, concrete, and bricks, etc. According to the requirements of construction engineering, construction engineering materials should meet the following performance:

(1)Building materials take a long time to stay strong and durable. For example, the columns and beams of frame structures in buildings, including steel bars, concrete, and so on, must have the strength and toughness to meet the design requirements.

(2)Building materials need to be able to meet certain temperature isolation or sound isolation. This aspect mainly refers to the building wall materials, including wall tiles, insulation layer, doors and windows, and other materials. In addition, these materials must also maintain a certain degree of durability.

(3) Building materials must also be able to adapt to different environmental conditions. Because of the great difference of the natural environment in China, the four seasons of spring, summer, autumn, and winter also have a great influence on the construction environment, and the building materials should be able to meet the requirements of construction under different environments.

\subsection{Construction Engineering Material Testing Technology Analysis}

The detection technology of different building engineering materials is different. This paper analyzes the detection technology of cement, steel bar, and wall material.

\subsubsection{Cement Testing Technology}

Cement is a kind of high strength powdery hydraulic inorganic cementitious material. Add water to the cement for stirring, and the cement can change from powder to slurry. Slurry-titted cement can cement stone, sand, and other materials firmly together and can harden in air or water. Cement can be divided into general cement and special cement. Civil engineering buildings are mostly general cement, that is, six categories of cement in accordance with GB175-2007 regulations. Cement is widely used in the construction engineering industry in our country. It can be said that the quality of cement plays an important role in engineering construction projects. If there are serious problems in cement quality, it will bury hidden dangers for the safety of buildings in the long run, affect the experience and even personal safety of residents or other users, and may directly endanger the safety of personnel on construction sites in the short term. Cement testing methods and technical requirements are specified in the General Portland Cement (XG2-2014), the cement testing standard formulated by our country. The standard shall check whether the cement factory quality certificate and signature and seal are complete, and also carefully check the validity period of cement. If the cement has expired, further re-examination is required to see if the numerical standards meet the specifications.

Cement avoid moisture caking, avoid exposure to dry, avoid low temperature freezing, avoid high temperature and heat, avoid base dirty soft, avoid aggregate impure, avoid water ash thick, avoid acid corrosion. The specific gravity of standard cement is 3 to 1 , and the finer the particles, the faster the hardening. The setting time of cement should be tested by a special tester. The strength of cement should conform to the national standard, the volume stability is good, the hydration heat is within the standard range, and the standard consistency is reached. In addition, we also need to pay attention to the update of cement testing standards and improve the anti-fouling standards of cement in time.

\subsubsection{Steel bar testing technology}

Steel bar mainly refers to the steel used in reinforced concrete and the steel used in prestressed reinforced concrete. Its cross section is generally round and square. The types of steel bars can be divided into torsional steel bars, smooth round steel bars, and ribbed steel bars. Steel bars are widely used in various building structures, especially high-rise buildings, large heavy buildings are inseparable from steel bars, steel bars are their skeleton, which plays a key role in the quality of buildings. At present, there are many standards for steel bar testing in our country, including Steel for Reinforced Concrete Part 1: Hot rolled round steel bar (GB1499.1-2017) and so on. Generally speaking, the principle of steel bar quality is to investigate the minimum reinforcement ratio and replace the steel bar according to the principle of equal area.

When testing the steel bar, the first is to check its production date, test report, certificate of competency, to confirm that there are no errors before the re-inspection work. The emphasis of steel bar detection is to detect the size, weight, technology, mechanical properties, and so on. In terms of appearance inspection, in a batch of steel bars 
by taking $5 \%$ of the sample, check its surface for cracks, laminated, uneven, or other deviations. In the mechanical properties test, two steel bars were extracted and cut into 2 sections for tensile and cold bending tests. If there are unqualified results, more than double the number of repeated tests should be extracted. If there are still unqualified cases, the unqualified steel bars of this batch should not be used. Finally, according to the detailed records of the test, the performance and risk of steel bar in engineering construction are estimated.

\subsection{Wall Material Testing Technology}

There are many kinds of wall materials, most of them belong to environmental protection building materials, the quality is small, the cost is low, the heat insulation, sound insulation, and moisturizing effect are better. With the development of building engineering technology and the improvement of building construction technology, many new wall materials are constantly appearing, such as small concrete hollow block, fiber gypsum board, ceramsite cutting block, and so on. The raw materials of wall materials are generally fly ash, coal gangue, slag and stone powder, and other wastes. In the process of testing, the inspectors should detect bricks of different properties, the quantity of detection is large, and the requirements of various indexes to be considered are also more. The detection of brick is mainly to detect its density, strength, shape, quality, and so on. Usually, it is not necessary to consider the flexural strength of brick. The compression strength, density, and thermal conductivity of wall insulation materials should be tested. For the possible errors and hidden dangers, it should make a good plan in advance, improve the quality of inspectors, and avoid all kinds of problems caused by testing errors.

\section{Key points of quality inspection technology for building engineering materials}

In the process of carrying out the inspection of building engineering materials, in order to complete the inspection task efficiently, accurately, and scientifically, we must deeply study all aspects of technical inspection. Testing personnel, testing time, testing equipment, and testing technology must meet the requirements of the specification, in order to achieve accurate, convenient, and efficient detection. In addition, we should make full use of raw materials to promote new technologies, new materials, and new processes.

\subsection{The sampling process meets the standard requirements and strengthens sample management}

The detection of building engineering materials generally includes three levels, the first is the detection of chemical properties, that is, to understand the chemical properties of the internal substances of engineering materials, so as to understand whether their basic characteristics meet the building requirements. such as determining its density, ignition point, etc. The second level is to study its processing technology, the same raw materials, after different processing technology will show a completely different form. The second level is to study its processing technology. The same raw materials will show completely different forms after different processing processes. The third is to detect the mechanical forming structure of building engineering materials. The load-bearing capacity of the material inside the building is evaluated by testing the tensile force, pressure, and so on.

The sampling process should be standardized representative sampling, otherwise it will lose the significance and value of detection. There are many kinds of building engineering materials, so we must carry out the inspection work through the sample. The sample is the cornerstone of the detection. If there is an error in the sampling process, the subsequent detection will be wrong. Comply with scientific specifications when sampling construction materials, testers should ensure that the sample is accurate and fill in relevant sampling reports. In addition, sampling is generally used to extract multiple samples from different parts of the same material, so the sampling position should be representative, and a little deviation can not be summarized by the sample. Therefore, the sampling work should meet the requirements of standardized and representative sampling in quantity and quality.

\subsection{Upgrading construction materials testing technology and making full use of modern information technology}

On the basis of correct standard sampling, construction engineering material testing technology is the key to carry out the work. There are three main detection techniques: loading speed detection, specimen size, and accuracy detection, and error detection. Sample detection can not be directly equivalent to physical material detection. Under the laboratory conditions of quality detection, due to the rapid loading of various velocities and loads, under different temperature conditions, some numerical indexes of many testing materials will deviate from the material itself. Strictly according to the loading speed of standard engineering materials in the detection, and within a reasonable range of the lowest value. Similarly, the shape and size of the sample must meet the requirements of the standard specimen, otherwise there will be problems inaccuracy. To ensure that the sample is correct, size standards, but also to strengthen the operator's testing technical level, must strictly abide by the inspection materials standards, specifications, and procedures, further reduce the error. At the same time, for test results and data, advanced software and data analysis equipment should be used to effectively process the data in order to scientifically and quantitatively evaluate the quality and utility of materials. 


\subsection{Improve the system construction, improve the technical level of testing personnel}

In order to further do the inspection of building engineering materials and ensure the effectiveness and safety of the test results, it is necessary to do a good job in the construction of the system. There should be a perfect system for the specific process, test standard, post system of personnel at all levels, and the storage of test results. Only in this way can the quality of testing work be continuously improved and optimized according to the development of information technology. The testing of building engineering materials has certain particularity, and the instruments and equipment will also cause losses and failures over time and personnel use. Therefore, it is necessary to ensure the proper custody of instruments and equipment. For some weighing precision equipment, regular calibration. Timely maintenance of testing equipment to ensure the accuracy of testing data.

In order to further eliminate the adverse effects of human causes on the test results, the technical training and guidance of the testing personnel should be carried out regularly. On the one hand, strengthen the threshold of testing personnel to ensure that they have relevant professional knowledge and operational practice. On the other hand, through training, lectures, online and offline learning and other ways, the practice of testing personnel to continue to carry out learning and upgrading activities, cultivate their professional technical level and comprehensive quality, promote high-quality engineering construction.

\section{References}

1. Wang Li. Analysis on the Application of Construction Engineering Materials Testing Technology[J]. Jiangxi Building Materials: Quality Control and Testing. 2019

2. Wu Jun, Technical Analysis of Engineering Building Materials Inspection, Quality Inspection of Building Materials[J]. 2020

3. Fan Peng. Research on Building Engineering Materials Management [D], Qingdao University of Technology. 2017

4. Lai Shuiqing. Analysis of Building Engineering Materials Detection Technology [J]. Wisdom Management, No .8, 2017

5. Zheng Guoqing. Concrete Testing Technology in Construction Engineering Quality Inspection[J]. No.8, 2020 